\title{
The Construction of Curricular System for College Volunteer Service in the New Era
}

\author{
Wang Jianjian ${ }^{1 *}$, Liang Haochuan ${ }^{1}$, Shen Guofang ${ }^{2}$ \\ ${ }^{1}$ School of Automation, Wuhan University of Technology, Wuhan, Hubei 430070, China \\ ${ }^{2}$ School of materials science and engineering, Wuhan University of Technology, Wuhan, Hubei 430070, China \\ *Corresponding author.Email: wang1jian9jian88@whut.edu.cn
}

\begin{abstract}
College students' volunteer service is an important public social welfare, which contributes to social security and stability, economic construction and the construction of social morality. At present, the construction of college students' voluntary service curriculum system needs further improvement. In the process of carrying out college students' voluntary service activities, problems such as lack of theoretical guidance, systematic training, practice platform and feedback are exposed. By analyzing college students volunteer service present situation in the construction of curriculum system, comparing the different college students' volunteer service,the paper analyzes problems existing in the process of college students' volunteer service curriculum system construction and puts forward reasonable proposals based on the feedback on the construction to promote college students' volunteer service long-term and institutional development, thus cultivating young students' responsibility, rules and dedication consciousness.
\end{abstract}

Keywords: volunteer service, curriculum system, colleges and universities, feedback

\section{Introduction}

In recent years, China's volunteer work is booming, college students as the main force of volunteer service has been placed with higher mission and requirements. "We will promote credibility building, institutionalize volunteer services, and heighten people's sense of social responsibility, awareness of rules, and sense of dedication"[1], is a higher requirement of the party and the state for the voluntary service in Colleges and universities. As an important social public welfare undertaking, college students' voluntary service has been recognized by more and more people after years of continuous practice. It plays an important role in supplementing social security, maintaining social security and stability, serving economic construction and social morality construction, and is of great significance in promoting the progress of the whole society. Exploring and constructing a good curriculum system for college students' volunteer service can effectively provide theoretical guidance and systematic training for college students' volunteer service activities, understand their actual difficulties and needs, and promote the long-term and institutionalized development of volunteer service work.

\section{Current situation of university volunteer service and curriculum system construction}

\section{1. practical application for the construction of voluntary service curriculum system}

The form of voluntary service for college students is gradually changing to special, public welfare and community. However, a series of problems have been exposed in the process of carrying out the volunteer service for college students, such as lack of theoretical guidance, systematic training, continuity, feedback on training effect and diversified form of voluntary service. It is required to explore the construction of college students' volunteer service curriculum about how to make the volunteer service activities more formal and how to internalize the volunteer spirit and knowledge of the activities.

The ways to realize the curriculumization of volunteer service include perfecting the educational goals and contents of volunteer service curriculum, theory teaching, practical platform and evaluation system. As for college students' volunteer service curriculum there are some difficulties in ideological cognition, resource support, system management and so on. Only by correctly understanding the curriculum, establishing the steering committee of voluntary service curriculum in colleges and universities, cooperating with each other, fully applying Internet technology, and constructing the curricular network platform, can voluntary service for college students become standardized, professional and long-term. The theoretical research on the construction of volunteer service curriculum in colleges and universities is not completed and the orientation is not clear, which is a constraint to the continuous development and normalization of volunteer service activities for college 
students. Due to the late start of voluntary service for college students in China, the research on the curriculum of voluntary service for college students mainly includes the value, function and motivation of voluntary service And it needs to be further strengthened and improved in the aspects of goal setting, content construction, system guarantee and effect feedback. The coverage of voluntary service needs to be further expanded, and the educational effect of voluntary service needs to be further improved. All this requires efforts in the construction of the course system of voluntary service, so that the professional quality and volitional quality of college students can develop simultaneously, and college students can receive the most comprehensive education.

\subsection{Research status and trends at home and abroad}

At present, college students' volunteer service mainly characterized by short term and activity type. The activity lacks attraction to volunteers, so it is difficult to deliver a lasting effect or form a healthy volunteer culture. On the other hand, the curriculum system of volunteer service needs further improvement and there is little reflection on the concept of volunteer service curriculum and feedback on the training effect, resulting in serious loss of volunteers. And it is difficult for volunteers to achieve ideal effect in the process of carrying out activities. Domestic scholars focus on how to put voluntary service into compulsory course or optional course, but there is little reflection on the concept of voluntary service. The research on voluntary service for college students mainly includes the value, function and motivation of voluntary service. Voluntary service for college students in China started late and needs further strengthening and improvement in system construction, curriculum system and system guarantee.

Abroad, the concept of "service learning" is generally adopted to realize the curriculumization of voluntary service, and the study and reflection of voluntary service are carried out. The goal is to cultivate civic awareness and become a sound citizen through voluntary service. And to integrate into the formal curriculum and institutionalization of schools, with formal credits or compulsory credits, which have been years of history. Take the United States as an example, the application of voluntary services in education has a wide impact on students, which can be highly summarized as 'Tell me and I will forget, Show me and I will remember, Involve me and I will understand' [2].

In foreign countries, the voluntary service is integrated with the school curriculum to form the voluntary service curriculum, which is gradually used, developed and improved. It forms an experiential teaching method with students' learning that taking school education and social needs as the three orientations, major and non-major courses as the main content, community service organization as the medium, activity record, credit certification, rewards and punishment incentive as the evaluation methods. It meets the needs of students' study, employment and development, effectively improves the comprehensive quality of students, enhances the effect of school teaching, creates social value, and realizes the benign development of students, schools and communities.

\section{OBJECTIVES AND KEY POINTS OF THE CONSTRUCTION OF COLLEGE VOLUNTEER SERVICE CURRICULUM SYSTEM}

As for college students' volunteer service curriculum there are some difficulties in ideological cognition, resource support, system management and so on. Only by correctly understanding the curriculumization, establishing the steering committee of voluntary service curriculum in colleges and universities, cooperating with each other, fully applying Internet technology, and constructing the curricular network platform, can voluntary service for college students become standardized, professional and long-term.

\subsection{Objectives of the construction of voluntary service curriculum system}

The construction of voluntary service curriculum system mainly includes the establishment of educational objectives, the formulation of teaching contents (including theoretical courses and practical courses), the guarantee of rules and regulations, and the establishment of feedback system. The goal setting should conform to the development trend of the times, adapt to the characteristics of college students, and effectively use the Internet and other emerging technologies. In terms of the formulation of teaching content and theoretical research, this paper mainly starts from the perspective of professional teachers, summarizes and analyzes the development status of the voluntary service curriculum system for college students, demonstrates and analyzes the existing voluntary service curriculum system, and conducts in-depth research on the development of voluntary service curriculum, textbook compilation and theoretical research. In terms of pragmatic research, we mainly set up a platform with schools, communities and governments to provide volunteer service practice opportunities. At the level of institutional guarantee, the state, society and universities should provide corresponding institutional guarantee to protect the rights and interests of volunteers and promote the longterm development of voluntary services. In terms of the establishment of the feedback system, through the communication with the instructors, volunteers and recipients of the volunteer service team, we can share the experience of volunteer service, understand the demand for volunteer service, feel the effect of volunteer service, and further improve the construction of the course system of volunteer service through the feedback of training, practice and effect of volunteer service. 
Through the research on the construction of college students' voluntary service curriculum system, a college students' voluntary service curriculum system is established based on the combination of explicit curriculum and implicit curriculum and supported by theoretical curriculum, practical curriculum and expanded curriculum. It enhances the effectiveness of ideological and political education of contemporary college students, increase the enthusiasm and initiative of college students to participate in voluntary services, and build a long-term mechanism of college students' voluntary services.

\subsection{Key points and difficulties in the construction of voluntary service curriculum system}

\subsubsection{Objective establishment of college students' voluntary service curriculum system}

The goal of college students' voluntary service curriculum is to realize the mutual development of students, universities and society. From the perspective of students, course should improve their professional knowledge, learning ability and practical ability, so as to promote the cultivation and all-round development of comprehensive quality. From the perspective of schools, schools should combine professional education with voluntary services, innovate the teaching model of curriculum, and integrate the fundamental task of moral education into the whole process of education. From the perspective of society, the curriculum should meet the needs of society and combine the teaching objectives with the latest needs of society.

\subsection{2 content arrangement of college students' voluntary service curriculum system}

The curriculum should combine theory, practice and sharing, which not only needs systematic theoretical system support, but also needs practical experience sharing to supplement. The three parts should jointly cultivate college students' volunteer spirit. Theory teaching is the foundation. Practice teaching is the core and experience sharing is the expansion.

\subsubsection{Assessment methods of college students' voluntary service curriculum system}

The content arrangement of volunteer service curriculum is quite different from that of traditional courses, so it is difficult to set up the assessment methods. The assessment method should be scientific and reasonable, which should not only consider the scientific rigor of theoretical teaching, but also consider the operability of practical links.

\subsubsection{Feedback on the effect of college students' voluntary service course system}

Feedback refers to the process of returning the output of the system at the input end and changing the input in some way, thus affecting the system function. The establishment of voluntary service curriculum system is aimed at providing better support for voluntary service and making voluntary service activities professional, standardized and practical. Therefore, feedback needs to be incorporated into the curriculum construction system.

The concept 'Feedback' is introduced in voluntary service curriculum system to build curriculum content with target setup, evaluation of curriculum effect, feedback effect, eliminate the deviation from the standard, and build 'Target - training - feedback - improvement-target' the closed loop curriculum system, so as to enhance the actual effect of ideological and political education of contemporary university students, enhance the enthusiasm and initiative of college students to participate in volunteer service activities, and then build a long-term mechanism of college students volunteer service.

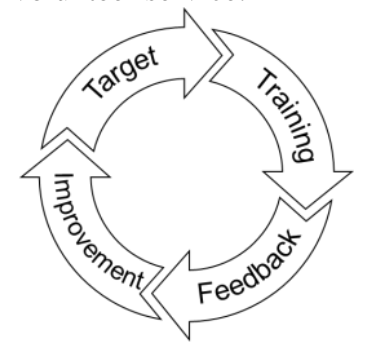

\section{MULTIDIMENTIONAL CONSTRUCTION OF VOLUNTEER SERVICE CURRICULUM SYSTEM}

\subsection{Transform the ideas}

With the development of the society, the ways and ideas of volunteer service have changed a lot. The goal of the construction of volunteer service curriculum system is to develop into institutionalized, job-oriented, professional and regular development, and establish a new model of volunteer service that combines online and offline. Based on their actual situation, colleges and universities can realize their recruiting effectively to carry out extensive online volunteer service[3]. Take advantage of the Internet development, expand the new space of volunteer service, and open up a new situation of volunteer service for college students in such links as publicity, recruitment and training, supervision and management, feedback and improvement. The concept of "service learning" is used to realize the curriculumization of voluntary service, and the learning reflection is carried out. The goal is to cultivate the civic consciousness of voluntary service and become a reliable citizen, so as to integrate into the formal curriculum and institutionalization of the school. 
the curriculum training, build a diversified voluntary service course evaluation system, effectively find the problems in the course system, and improve the effect of course training. Establish the supervision mechanism of volunteer service, regulate every link of volunteer service, find out the problems of volunteers and volunteer service and adjust in time.

The process of College Students' service society is a process of mutual information exchange between the volunteers and the audience[5]. We should evaluate and get feedback on the effect of volunteer service, timely understand the changes of participants and the satisfaction of recipients, and construct the feedback mechanism of service effect. Voluntary feedback tracking system should be built to track the volunteers who join the voluntary service through "Voluntary feedback", provide them with voluntary service curriculum, unite more volunteer forces through diversified activities, so voluntary service gets a virtuous circle.

\section{ACKNOWLEDGMENT}

This paper is the stage achievement of the youth work research association of hubei university in 2019-2020, project no.: GYHYB2019006

\section{REFERENCES}

[1] Xi Jinping. Secure a Decisive Victory in Building a Moderately Prosperous Society in All Respects and Strive for the Great Success of Socialism with Chinese Characteristics for a New Era-Delivered at the 19th National Congress of the Communist Party of China[Z]. beijing,2017.

[2] Ross, M. E. T. Linking Classroom Learning to The Community Through Service Learning[J]. Journal of Community Health Nursing, 2012(29):53-60.

[3] Pan Guoling. A Study on the Effectiveness of College Students' Volunteer Service - Taking the Communist Youth League Care for the Children of Migrant Workers' Volunteer Service Action Colorful Cabin as a Case[P]. Proceedings of the 4th International Conference on Economics, Management, Law and Education (EMLE 2018),2018.

[4] Lian-song Wu,Hong-lian Liu. On the Exploration of the Educational Function of College Students' Volunteer Service Activities[P]. Proceedings of the 3d International Conference on Applied Social Science Research,2016.

[5] Tianyun Pei. College Students Volunteer Service: a Platform for Carrying out the Effective Practice of Citizen Education in Colleges and Universities[P]. 
Proceedings of the 2016 International Conference on

Education, Management, Computer and Society,2016. 